\title{
Maximum Anaerobic Power in Adult Alpine Ski Racers
}

\author{
Tetsu Miura \\ Niigata Health and Sports Medical Science Center \\ 67-12 Seigoro, Chuou-ku, Niigata-City, Niigata, 950-0981 JAPAN \\ E-mail: tetsu-m@cameo.plala.or.jp \\ [Received September 8, 2014; Accepted October 23, 2015; Published online January 8, 2016]
}

\begin{abstract}
Alpine ski competition demands high-power output. However, the target maximum anaerobic power (MAnP) on a bicycle ergometer and its relationship to competitive performance has not yet been clarified for adult alpine ski racers. The aim of this study was to determine the target MAnP of adult alpine ski racers and its relationship to their performance. Participants included 14 male and 10 female alpine ski racers, who had graduated from high school. The MAnP was divided by the participant's weight to determine relative power to body weight (BW). Competitive performance was assessed in terms of the number of points on the International Ski Federation (FIS) slalom (SL) and giant slalom (GS). Both male and female racers showed either significant or marginally significant correlations $(r=-0.40$ to -0.69$)$ of MAnP and MAnP/BW with the FIS SL and GS point totals. These results indicated that there was a relationship between MAnP and MAnP/BW and alpine ski competitive performance at the national level for both male and female competitors. In this study, the targets of the MAnP and MAnP/BW in FIS SL and GS were approximately $1300 \mathrm{~W}$ and $17 \mathrm{~W} / \mathrm{kg}$ for males, and $900 \mathrm{~W}$ and $15 \mathrm{~W} / \mathrm{kg}$ for females, respectively. These values are appropriate indicators of competitive performance.
\end{abstract}

Keywords: maximum anaerobic power, competitive performance, alpine ski, target power, bicycle ergometer

\section{Introduction}

As an estimate of alactic power, Ayalon et al. (1974) and Katch et al. (1977) evaluated the power of the first $5 \mathrm{~s}$ of exercise and the peak power (PP) at several specific loads on a bicycle ergometer. However, the power output was found to vary depending on the load. Therefore, for accurate measurement of maximum anaerobic power, the relationship between the load and the power output must be considered. Dotan and Bar-Or (1983) measured power during all-out pedaling for $30 \mathrm{~s}$, five times, at different loads, and performed quadratic regression to estimate the maximal power. This method requires more than four measurements for the calculation. Nakamura et al. (1985) obtained a maximal power value using three measurements, one for each 10-s period (Maximal Anaerobic Power: MAnP). Previously, to obtain the maximum power, Ayalon et al. (1974) had participants pedal a bicycle ergometer for $30 \mathrm{~s}$ and measured the power for the first $5 \mathrm{~s}$ and the total work for $30 \mathrm{~s}$. Since then, many studies have measured the peak power at each specific load and exercise time as the maximum power (Katch et al., 1977). However, MAnP marked the highest power output, proving to be the true maximum power. Similar results were obtained by Nakamura et al. (1985). Therefore, the MAnP test is considered the most appropriate for measurement of maximal instantaneous power. In addition, the small number of measurements reduces the physical burden on athletes, thus allowing testing of many athletes.

The alpine ski competition demands high-power output (Haymes and Dickinson, 1980). A number of previous studies have addressed the relationship between anaerobic power and competitive performance for adult male alpine ski racers. Haymes and Dickinson (1980) demonstrated such a relationship using the stair run test (Margaria et al., 1966) and vertical jump for assessment of competitive performance in adult male alpine ski racers. However, the relationship between maximum anaerobic power on a bicycle ergometer and competitive performance has not yet been clarified for adult male and female ski racers.

Therefore, the aim of this study was to clarify the utility of maximum anaerobic power on a bicycle ergometer to assess the international level in alpine 
ski racers. The study also attempted to clarify the direction of maximum anaerobic power training for such alpine ski racers by investigating the most suitable target maximum anaerobic power at international level and the characteristics of the relationship between maximum anaerobic power and performance in both adult male and female alpine ski racers. It was anticipated that the results would be helpful for improving the planning of training for such competitors.

\section{Methods}

\subsection{Participants}

The participants included 14 male and 10 female alpine ski racers who had graduated from high school (males aged 21.6 \pm 2.1 years and females aged $21.1 \pm 2.3$ years). Their levels of competition, varying from international to regional, were roughly equivalent to national competition prize-winner level on average (six males and six females, i.e., at least half the number of participants). Tests were conducted between August 2002 and October 2014 at the Niigata Health and Sports Medical Science Center. Participants were tested on any day they desired during the testing period. Before the tests, approval was obtained from the ethics committee of the Niigata Health and Sports Medical Science Center. Procedures and risks of the tests were explained to the athletes, and their approval was obtained. The Medical examinations including physical and laboratory testing who performed by physical tests and measurement before every performed tests.

\subsection{Physical measurements of participants}

Table 1 displays the participants' physical measurements in terms of height, weight, percentage body fat, and fat-free mass. Percentage body fat ( $\%$ fat) was estimated from body density (Brozec et al., 1963). Body density was predicted by skinhold thickness over the triceps and subscapular regions (Nagamine and Suzuki, 1964). The fat mass was multiplied by body weight and \%fat. Lean body mass (LBM) was determined by subtracting fat mass from body weight.
Table 1 Physical characteristics of participants.

\begin{tabular}{ccccccc}
\hline & & $\begin{array}{c}\text { Age } \\
\text { year }\end{array}$ & $\begin{array}{c}\text { Height } \\
\text { cm }\end{array}$ & $\begin{array}{c}\text { Weight } \\
\text { kg }\end{array}$ & $\begin{array}{c}\% \text { Fat } \\
\%\end{array}$ & $\begin{array}{c}\text { LBM } \\
\text { kg }\end{array}$ \\
\hline \multirow{2}{*}{ Male } & mean & 21.6 n.s. & $173.6^{* *}$ & $73.4^{* *}$ & $12.6^{* *}$ & $64.1^{* *}$ \\
& S.D. & 2.1 & 5.3 & 8.0 & 1.7 & 6.5 \\
\hline \multirow{2}{*}{ Female } & mean & 21.1 & 159.7 & 60.5 & 18.9 & 49.1 \\
& S.D. & 2.3 & 4.3 & 3.9 & 2.5 & 3.9 \\
\hline \multirow{2}{*}{ Female/Male \% } & & 92.0 & 82.4 & 150.2 & 76.6 \\
\hline
\end{tabular}

Student's t-test Male vs. Female, ${ }^{*} \mathrm{p}<0.05,{ }^{* *} \mathrm{p}<0.01$

\subsection{Power tests}

The participants performed a 20-min warm-up (including pedaling a bicycle ergometer for $5 \mathrm{~min}$ or longer at 50-60 W load and 60-80 rpm). To clarify the characteristics of the anaerobic power test based on maximum power and the relationship between competitive performances, the MAnP test (Nakamura et al., 1985) was conducted using an electromagnetic brake bicycle ergometer (PowerMax VII, by Combi Co., Ltd.). Immediately before taking a maximal anaerobic power test, the participant conducted trial maximal pedaling three times as a warm-up; the first time with a light load (2-4 kp; warm up on the same load as for the first test), the second time with a very light load $(0.1 \mathrm{kp}$; warm up for speed), and the third time with a heavy load (6-10 kp; warm up for heavy load). Such a warm-up pedaling period reduced operational errors and enabled pedaling at maximum capacity. Then, after a 3-min rest, the participant conducted of 10-s of maximal pedaling for three sessions at different loads, with a 2-min rest after each pedaling set. The three loads selected ranged from 3 to $11 \mathrm{kp}$, based on the participant's body weight and the determined optimal maximal output. From the PP outputs of the three pedaling sets, the maximum power was calculated. For the MAnP test, shoes and pedals were fixed to each other with strips or with binding pedals and toe clip-attached shoes.

\subsection{Competitive performances}

The competitive performances used were based on the point totals for the International Ski Federation (FIS) slalom (SL) and giant slalom (GS). These point scores were the means of the best two race points (RP) from each season. The higher the competitive 
performance, the lower the points awarded (the best being zero). The equation employed was:

$\mathrm{RP}=(\mathrm{Tx} \times \mathrm{F}) / \mathrm{To}-\mathrm{F}$.

where $\mathrm{RP}=$ race points; To $=$ time of winner in seconds; $\mathrm{Tx}=$ time of the classified competitor in seconds; $\mathrm{F}$ (these values different in each season), $\mathrm{SL}=$ 610-720; GS $=870-980$.

\subsection{Data processing}

The MAnP was divided by the participant's weight to determine the relative power to body weight (BW). The purpose of this procedure was to conduct evaluations in a situation resembling sporttraining fields. The analysis involved the t-test to compare males and females with respect to MAnP and $\mathrm{MAnP} / \mathrm{BW}$.

For the relationship between MAnP, MAnP/BW, and competitive performance, Pearson's productmoment correlation coefficient was calculated and significance determined, if any. Statistical significance on test of correlation coefficients was assessed using $95 \%$ confidence intervals, and $p<0.05$ and $p<0.01$ were considered significant, $p<0.10$ being considered marginally significant.

The higher the competitive performance, the lower the FIS point total awarded (the best being zero). Therefore, when setting targets for MAnP as an indicator the highest FIS competitive point total was zero. The higher power for the target derives from higher competitive performance. This procedure assessed targets of MAnP as the intercepts in single regression formulas. This study aimed to clarify the utility of MAnP on a bicycle ergometer for attaining the international level in alpine ski racers.

\section{Results}

\subsection{Characteristics of the participants}

Table 1 shows the physical characteristics of the participants and their female-to-male ratios (\%). The males were taller and heavier, while females had a greater \% fat. Therefore, the female-to-male ratio of LBM was lower than that of body weight, indicating the typical differences between males and females.

Table 2 shows the FIS SL and GS point totals for male and female participants. The participants has a
Table 2 The FIS SL and GS point totals of participants.

\begin{tabular}{crrcc}
\hline & \multicolumn{2}{c}{ Male } & \multicolumn{2}{c}{ Female } \\
& \multicolumn{1}{c}{ SL } & GS & SL & GS \\
\hline mean & 103.3 & 87.9 & 39.6 & 39.2 \\
S.D. & 91.6 & 67.2 & 17.9 & 18.9 \\
min & 22.4 & 26.4 & 15.4 & 12.8 \\
max & 298.3 & 239.2 & 62.8 & 68.6 \\
\hline
\end{tabular}

Table 3 The means and standard deviations of maximum anaerobic power and these relative powers to body weight.

\begin{tabular}{lccc}
\hline & & MAnP & MAnP/BW \\
& & $\mathrm{W}$ & $\mathrm{W} / \mathrm{kg}$ \\
\hline \multirow{2}{*}{ Male } & mean & $1217.8^{* *}$ & $16.6^{* *}$ \\
& S.D. & 188.5 & 2.2 \\
\hline \multirow{2}{*}{ Female } & mean & 839.5 & 13.9 \\
& S.D. & 70.6 & 1.0 \\
\hline \multicolumn{2}{l}{ Female/Male \% } & 68.9 & 83.5 \\
\hline
\end{tabular}

Student's t-test, ${ }^{*} \mathrm{p}<0.05,{ }^{* *} \mathrm{p}<0.01$

wide range of FIS SL and GS point totals from a high competitive performance of 12.8 points to a low of 298.3 points.

\subsection{Comparison of the MAnP and MAnP/BW be- tween males and females}

Table 3 displays the MAnP, the MAnP/BW, and the female-to-male ratios. For the MAnP and MAnP/BW, males showed significantly higher statistical values than females. The female-to-male percentage in the MAnP was $68.9 \%$, and that for the MAnP/BW was $83.5 \%$.

\subsection{Relationship between competitive performance and physical characteristics in males and females}

Table 4 shows the correlations between competitive performance (FIS SL and GS point totals) and physical characteristics in males and females. These correlations were not significant $(r=0.33$ to -0.44$)$ except for a medium significant correlation between the FIS SL and GS point totals and \% fat in males $(r=0.54$ and 0.52$)$, the FIS SL and GS point totals and age in females $(r=-0.78$ and -0.68$)$, and the FIS GS point totals and height in females $(r=0.60)$. 
Table 4 The relationship of physical characteristics of participants to FIS SL and GS point totals.

\begin{tabular}{clllrrr}
\hline & & Age & Height & Weight & $\%$ Fat & \multicolumn{1}{c}{ LBM } \\
\hline \multirow{2}{*}{ Male } & SL point & -0.34 n.s. & -0.25 n.s. & 0.25 n.s. & $0.54^{*}$ & 0.16 n.s. \\
& GS point & -0.24 n.s. & -0.44 n.s. & -0.17 n.s. & $0.52^{*}$ & -0.27 n.s. \\
\hline \multirow{2}{*}{ Female } & SL point & $-0.78^{* *}$ & 0.33 n.s. & -0.13 n.s. & 0.09 n.s. & -0.14 n.s. \\
& GS point & $-0.68^{*}$ & $0.60^{*}$ & 0.14 n.s. & -0.21 n.s. & 0.21 n.s. \\
\hline
\end{tabular}

** $\mathrm{p}<0.01, * \mathrm{p}<0.05,{ }^{\dagger} \mathrm{p}<0.10$

Table 5 The relationship of maximum anaerobic power and relative power to FIS SL and GS point totals and the intercepts in single regression formulas.

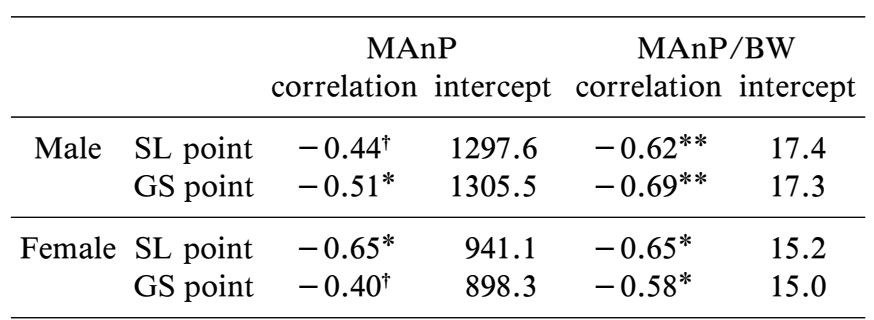

${ }^{* *} \mathrm{p}<0.01,{ }^{*} \mathrm{p}<0.05,{ }^{\dagger} \mathrm{p}<0.10$

\subsection{Relationship between competitive performance and the MAnP, MAnP/BW in males and females}

Table 5 shows the correlations between competitive performance (FIS SL and GS point totals) and the MAnP and MAnP/BW in males and females. The male and female alpine ski racers showed significant or marginally significant correlations of MAnP and MAnP/BW with the FIS SL and GS point totals $(r=-0.40$ to -0.69$)$.

\subsection{MAnP and MAnP/BW targets}

The targets of the MAnP and MAnP/BW were set on the power intercepts in single regression formulas (Table 5). These targets in terms of the FIS SL and GS were about $1300 \mathrm{~W}$ and $17 \mathrm{~W} / \mathrm{kg}$ for males and $900 \mathrm{~W}$ and $15 \mathrm{~W} / \mathrm{kg}$ for females, respectively.

\section{Discussion}

\subsection{Physical characteristics and participant com- petitive performances}

Previous studies have reported the physiological profiles of elite alpine skiers (Haymes and Dickinson, 1980; Brown and Wilkinson, 1983; White and
Johnson, 1991; Wakayama et al., 1998; Impellizzeri et al., 2009; Maffiuletti et al., 2009). These included the mean height $181.0-174.7 \mathrm{~cm}$, weight $87.0-73.3$ $\mathrm{kg}$, and \% fat $15.8 \%-6.1 \%$ in males, and the mean height $166.0-165.1 \mathrm{~cm}$, weight $65.1-58.8 \mathrm{~kg}$, and $\%$ fat $24.5 \%-13.1 \%$ in females. The participants in the present study were shorter in height and lighter in weight than those in previous studies. However, the \%fat of males and females in this study was similar to the ranges in previous studies. It was thought that these weight differences may have been due to the competitive level. Table 2 shows the SL and GS point totals for male and female subjects. The higher the competitive performance, the fewer points awarded (the best being zero). In this study, the participants' competitive levels ranged widely from international to regional, whereas those in previous studies ranged from fairly high international to national. Weights were lighter, but \%fat was the same. Therefore, it could be considered that our participants had less muscle mass. To obtain higher performance, a greater muscle mass might be necessary.

Analysis of the relationship between competitive performance (FIS SL and GS point totals) and physical characteristics in males and females demonstrated a medium correlation (significant, $r=0.54$ and 0.52 ) between FIS SL and GS point totals and \% fat in males. Haymes and Dickinson (1980) reported that the correlation between FIS SL point totals and $\%$ fat in national U.S. male alpine ski racers was highly significant $(\mathrm{r}=0.78$, strong correlation). However, the participants in that study were competing only at national level. Thus, it may be considered that the higher competition level resulted from the tendency toward a stronger correlation between competitive performance and \%fat. These correlations were possible because of rapid lateral transfer in SL and GS. 


\subsection{Differences in MAnP and MAnP/BW by sex}

The female-to-male percentage of MAnP in this study was $68.9 \%$. The female-to-male percentage in MAnP/BW was $83.5 \%$, being higher than the percentage for the absolute power value. For international, national, and regional male and female alpine ski racers, White and Johnson (1991) reported a comparison of vertical jump and maximal power in the Wingate 30-second test. However, that study did not compare the power in both males and females. The female-to-male percentages for the vertical jump and maximal power in the Wingate 30 -second test for the international group were $72.0 \%$ and $80.0 \%$, respectively, whereas those for the vertical jump power/BW and maximal power/BW were $90.2 \%$ and $100.0 \%$, respectively. Similar results were obtained in the present study, the female-tomale percentages for each power/BW calculation being higher than for each power calculation. Specifically, the female-to-male percentages in this study tended to be lower. The power and power/BW were higher in males than in females, being probably attributable to the known differences between the sexes (especially LBM and \%fat).

\subsection{Characteristics of MAnP and MAnP/BW}

Wakayama et al. (1998) investigated the physical characteristics of the Japan national male alpine ski team. Their MAnP mean value was higher than that in the present study $(1199.4 \mathrm{~W}$ and $16.3 \mathrm{~W} / \mathrm{kg})$. Yamane et al. (1996) also reported the physical characteristics of the Japan national junior female alpine ski race team (age $15.5 \pm 0.1$ years). The MAnP (819.2 W) was almost the same as that in the present study. The MAnP mean values in this study were almost the same in males and a little higher in junior females. Therefore, these values appear to be appropriate indicators of competitive performance.

\subsection{Relationship between the MAnP, the MAnP/ $\mathrm{BW}$, and competitive performance}

There were significant or marginally significant correlations of MAnP and MAnP/BW with the FIS $\mathrm{SL}$ and GS point totals in males and females $(\mathrm{r}=$ -0.69 to -0.40 ). These results indicated that there was a relationship between the MAnP and MAnP/
BW and average male and female alpine ski competitive performance at the national level. Therefore, it could be inferred that male and female alpine ski racers require a higher maximum power to compete at national level.

Haymes and Dickinson (1980) demonstrated a relationship between competitive performance and the stair run test $(r=-0.64$ for SL points and $r=$ -0.80 for GS points) or vertical jump $(r=-0.64$ for GS points) in adult male alpine ski racers. The loads for these powers were the body weights used in their previous study. The correlation coefficients in the previous study indicated a close relationship between the MAnP/BW and competitive performance. These results indicated that the $\mathrm{MAnP} / \mathrm{BW}$ is moderately correlated with competitiveness, and is an indicator of the higher power capability with the heavier load in the present study.

\subsection{Target of the MAnP and MAnP/BW}

The MAnP and MAnP/BW in the Japan national alpine ski team were reported to be $1295 \pm 89 \mathrm{~W}$ and $17.7 \pm 1.1 \mathrm{~W} / \mathrm{kg}$ in males (Wakayama et al., 1998) and $819 \pm 23 \mathrm{~W}$ and $14.1 \pm 0.4 \mathrm{~W} / \mathrm{kg}$ in junior females, respectively (Yamane et al., 1996). In the present study, targets of the MAnP and MAnP/BW in SL and GS were approximately $1300 \mathrm{~W}$ and 17 $\mathrm{W} / \mathrm{kg}$ for males and $900 \mathrm{~W}$ and $15 \mathrm{~W} / \mathrm{kg}$ for females, respectively. These were properly ascertained values and can thus be used as indicators of peak fitness required in alactic exercise.

\section{Acknowledgements}

We extend special thanks to the Director and staff of Niigata Health and Sports Medical Science Center for their support in this study. The author is grateful to Dr. Mochiyoshi Miura (A professor emeritus at Joetsu University of Eduation) and Prof. Tadashi Kobayashi (Hokkaido University of Education, Iwamizawa) for basic guidance, and to the athletes and their parents who participated in the physical tests at the Center and agreed to the use of data relevant to this study.

\section{References}

Ayalon, A., Inbar, O., and Bar-Or, O. (1974). Relationships among measurements of explosive strength and anaerobic power. In R. C. Nelson and C. A. Morehouse (eds.), Biomechanics IV (pp. 572-577). Baltimore: Univ. Park Press.

Brown, S. L. and Wilkinson, J. G. (1983). Characteristics of national, divisional, and club male alpine ski racers. Med. Sci. Sports Exerc. 15: 491-495.

Brozek, J., Grande, F., Anderson, J. T., and Keys, A. (1963). Densitometric analysis of body composition: Revision of 
some quantitative assumptions. Ann. N. Y. Acad. Sci., 110: 113-140.

Dotan, R. and Bar-Or, O. (1983). Load optimization for the Wingate anaerobic test. Eur. J. Appl. Physiol. Occup. Physiol., 51: 409-417.

Haymes, E. M., and Dickinson, A. L. (1980). Characteristics of elite male and female ski racers. Med. Sci. Sports Exerc., 12: 153-158.

Impellizzeri, F. M., Rampinini, E., Freschi, M., Maffiuletti, N. A., Bizzini, M., and Mognoni, P. (2009). Identification of the physical characteristics that discriminate between competitive levels and specialties of alpine skiers. In E. Müller, S. Lindinger, \& T. Stöggl (eds.), Science and Skiing IV (pp. 272-280). Maidenhead: Meyer \& Meyer Sport.

Katch, V., Weltman, A., Martin, R., and Gray, L. (1977). Optimal test characteristics for maximal anaerobic work on the bicycle ergometer. Res. Q., 48: 319-327.

Maffiuletti, N. A., Jordan, K., Spring, H., Impellizzeri, F. M., and Bizzini, M. (2009). Physiological profile of Swiss elite alpine skiers: A 10-year longitudinal comparison. In E. Müller, S. Lindinger, \& T. Stöggl (eds.), Science and Skiing IV (pp. 365-373). Maidenhead: Meyer \& Meyer Sport.

Margaria, R., Aghemo, P., and Rovelli, E. (1966) Measurement of muscular power (anaerobic) in man. J. Appl. Physiol., 21: 1662-1664.

Nagamine, S. and Suzuki, S. (1964). Anthropometry and body composition of Japanese young men and women. Hum. Biol., 36: 8-15.

Nakamura, Y., Mutoh, Y., and Miyashita, M. (1985). Determination of the peak power output during maximal brief pedaling bouts. J. Sports Sci., 3: 181-187.

Wakayama, A., Yanagi, H., Tamura, S., Tomosue, R., Yamane, M., and Matsui, H. (1998). The physical characteristics of Japanese elite male skiers. International Meeting of Sports Science Commemorating the 1998 Winter Olympic in Nagano, 43-47.

White, A. T. and Johnson, S. C. (1991). Physiological comparison of international, national and regional alpine skiers. Int. J. Sports Med., 12: 374-378.

Yamane, M., Kobayashi, T., and Ishige, Y. (1996). Physiological comparison of national and regional junior female alpine skiers. $1^{\text {st }}$ International Congress on Skiing and Science Abstracts: 294-295.

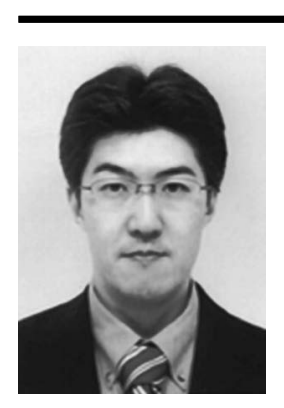

\section{Name:}

Tetsu Miura

Affiliation:

Niigata Health and Sports Medical

Science Center

Address:

67-12 Seigoro, Chuou-ku, Niigata-City, Niigata, 950-0981 JAPAN

\section{Brief Biographical History:}

2002-present A Chief, Niigata Health and Sports Medical Science Center

1999-2005 Doctoral Program, The Joint Graduate School in Science of School Education, Hyogo University of Teacher Education

1996-1999 Master's Program, Graduate School of Education, Hokkaido University of Education

1992-1996 Undergraduate Program, Faculty of Education, Yamagata University

\section{Main Works:}

- Miura, T., Miura, M. (2014). Turn skill analysis method of a skier's forward/backward motion on kinematics in Alpine skiing. Science and Skiing VI: 209-214.

-Miura, T., Miura, M. (2012). Relationship of physiological characteristics to competitive performance for junior high school and high school male alpine ski racers. Science and Skiing V: 298-307.

Membership in Learned Societies:

- International Congress on Science and Skiing

- Japan Society of Physical Education, Health and Sport Sciences

- Japanese Society of Physical Fitness and Sports Medicine

- Japanese Society of Biomechanics

-Japan Society of Training Science for Exercise and Sport

- Japanese Society of Ski Sciences

- Japanese Forum of Winter Sports Sciences 